\title{
Tratamento homeopático oferecido pelo Sistema Único de Saúde
}

\author{
Homeopathic treatment offered by the Unique Health System \\ Tratamiento homeopático ofrecido por el Sistema Único de Salud
}

\begin{abstract}
Resumo
O tratamento homeopático concedido pelo Sistema Único de Saúde chegou ao Brasil em 1840 e 1980 passou a ser oferecido o atendimento no sistema público, no sistema único de saúde utiliza-se a medicina complementar e tradicional, onde tais práticas envolvem a homeopatia, acupuntura. Acerca disso, teve como objetivo principal apresentar uma análise sobre o tratamento homeopático no SUS que hoje é reconhecida como uma especialidade médica e farmacêutica sendo uma ciência fundamentada em princípios da similitude, da experimentação patogenética, da diluição e o princípio do medicamento único. Foi realizado mediante pesquisa bibliográfica, em busca eletrônica nas bases de dados Lilacs, Scielo e Pubmed. Dentre os critérios de inclusão foram incluídos textos completos, artigos publicados últimos 7 anos (2014 a 2021), no idioma português, nas bases de dados eletrônicas já informadas. Como principal resultado observado através da pesquisa feita, ainda existe uma escassez de publicações de artigos e estudos que abordam sobre o tratamento homeopático oferecido pelo SUS. Ainda assim, a prática de cuidado é de fundamental importância para a qualificação de tais ações, assim como no cuidado integral à saúde e significativo para desenvolver os conhecimentos acerca da análise e da possibilidade de buscar compreender mais sobre o assunto que ainda é pouco explorado.
\end{abstract}

Palavras-chave: Homeopatia; Terapia complementar; Sistema Único de Saúde.

\begin{abstract}
The homeopathic treatment granted by the Unique Health System arrived in Brazil in 1840 and 1980 it began to be offered in the public system, in the unique health system complementary and traditional medicine is used, where such practices involve homeopathy, acupuncture. The main objective is to present an analysis of homeopathic treatment in SUS, which today is recognized as a medical and pharmaceutical specialty that is a science based on the principles of similitude, pathogenic experimentation, dilution, and the single drug principle. It was conducted by means of a literature search, in an electronic search in the Lilacs, Scielo, and Pubmed databases. Among the inclusion criteria were included full texts, articles published in the last 7 years (2014 to 2021), in Portuguese language, in the electronic databases already informed. As a main result observed through the research conducted, there is still a scarcity of publications of articles and studies that address the homeopathic treatment offered by SUS. Still, the practice of care is of fundamental importance for the qualification of such actions, as well as in integral and significant health care to develop knowledge about the analysis and the possibility of seeking to understand more about the still little explored subject.
\end{abstract}

Keywords: Homeopathy; Complementary therapy; Unique Health System.

\section{Resumen}

El tratamiento homeopático otorgado por el Sistema Único de Salud llegó a Brasil en 1840 y 1980 comenzó a ser ofrecido en el sistema público, en el sistema único de salud se utiliza la medicina complementaria y tradicional, donde tales prácticas involucran la homeopatía, la acupuntura. Sobre esto, tuvo como objetivo principal presentar un análisis sobre el tratamiento homeopático en el SUS que hoy es reconocido como una especialidad médica y farmacéutica siendo una ciencia basada en principios de similitud, de la experimentación patogenética, de la dilución y del principio de la medicina única. Se realizó mediante investigación bibliográfica, en búsqueda electrónica en las bases de datos Lilacs, Scielo y Pubmed. Entre los criterios de inclusión se incluyeron textos completos, artículos publicados en los últimos 7 años (2014 a 2021), en idioma portugués, en las bases de datos electrónicas ya informadas. Como principal resultado observado a través de la investigación realizada, aún son escasas las publicaciones de artículos y estudios que aborden el tratamiento homeopático ofrecido por el SUS. Aún así, la práctica asistencial es de fundamental importancia para la cualificación de dichas acciones, así como en la atención integral de la salud y significativa para 
desarrollar el conocimiento sobre el análisis y la posibilidad de buscar entender más sobre el tema que aún es poco explorado.

Palabras clave: Homeopátia; Terapia complementaria; Sistema Único de Salud.

\section{Introdução}

Em novembro de 1990 surgiu uma Lei (8.080) que define o Sistema Único de Saúde um conjunto de serviços e ações de saúde sendo regulamentado por órgãos públicos municipais, estaduais e federais. Sua finalidade é a assistência integral à saúde de todos os cidadãos de maneira universal e restrita e em sua previsão constitucional se expressa como um sistema único, integralizado e hierarquizado que engloba as ações e serviços de saúde pública do país. A criação do SUS é resultado da Reforma Sanitária, que iniciou nos anos de 1970 e foi consagrado na 8a Conferência Nacional de Saúde (1986).

Neste Sistema Único é utilizado a Medicina Complementar e a Tradicional, onde tais práticas envolvem a homeopatia, acupuntura, medicina antroposófica e fitoterapia. No que diz respeito, a presente pesquisa tem como objetivo abordar uma análise sobre o tratamento homeopático no SUS que hoje reconhecida como uma especialidade médica e farmacêutica sendo uma ciência fundamentada nos quatro princípios acima descritos: o princípio da similitude, o princípio da experimentação patogenética, o princípio da diluição (doses mínimas) e o princípio do medicamento único e ainda assim muitos usuários desconhecem a disponibilidade desse tratamento na saúde pública, tal qual do que se trata a fundo. A Homeopatia trata o indivíduo, assim pode ser utilizada em qualquer pessoa, desde recém-nascidos a idosos e assim como em qualquer doença, tanto nas agudas, como nas crônicas. Em todas as situações clínicas, a homeopatia pode ser associada de forma complementar a outras formas de tratamento com bons resultados e é muito importante este cuidado compartilhado com outros especialistas ou com outros profissionais de saúde. À vista disso, surge a seguinte problemática: Como o tratamento homeopático pode reduzir os custos do governo, na implementação das práticas complementares no Sistema Único de Saúde? Destarte, justificase para criar espaços e para a incorporação de diferentes saberes e práticas de saúde capazes de ampliar a abordagem no processo de entendimento das dimensões de saúde e adoecimento dos indivíduos e da coletividade, além de trazer o panorama mundial da homeopatia como especialidade, o dossiê abarca outras revisões sobre as linhas de pesquisa que fundamentam os pressupostos homeopáticos.

A proposta desse estudo destaca-se de modo mais detalhado, as motivações no qual é decidido a escolha da temática em questão e os objetivos propostos. Acredita-se também que se consegue ter um material capaz de reunir diversas reflexões teóricas necessárias para reflexão sobre o fenômeno estudado, assim é sustentado com base de pesquisas bibliográficas, livros, artigos postados na internet e reportagens em web sites para assim engrandecer e enriquecer o trabalho tal como partir disso surgiram questionamentos relacionados acerca do assunto.

\section{Metodologia}

O presente trabalho utiliza como metodologia a pesquisa qualitativa através de um bibliográfico. Segundo Gunther (2016), uma vantagem da pesquisa qualitativa é utilizar "dados que ocorrem naturalmente para encontrar sequências em que os significados dos participantes são exibidos e, assim, estabelecer o carácter de algum fenômeno".

Os critérios de inclusão artigos, teses, dissertações e demais estudos de caso nos últimos 7 anos (2014 a 2021), com descritores pesquisados no título e/ou resumo publicados que abordasse o tratamento homeopático oferecido ao SUS. Os critérios de exclusão foram monografias, livros, resumos em eventos, artigos que não atenderam a temática sendo revisões bibliográficas ou sistemáticas, artigos duplicados e que se encontravam nos idiomas inglês e espanhol (não redigidos em língua portuguesa).

O tipo deste estudo é feito através da pesquisa bibliográfica, pois para construir todos os aportes teóricos dentro deste trabalho foi necessária a posse de livros, artigos, dentre outros. A coleta de dados será realiza por estratégia de busca nas bases 
de dados: Lilacs, Scielo e Pubmed. A escolha dos estudos será realizada em constância da leitura dos títulos, resumos e por fim a leitura na íntegra.

Após a primeira seleção dos descritores, foram lidos os títulos dos artigos, os que não abordaram o tema específico serão excluídos, o mesmo foi feito após a leitura do resumo e do próprio conteúdo do artigo. Em cada etapa, foi anotada a quantidade numérica selecionada para confecção de fluxograma referente à seleção dos estudos e o motivo da exclusão dos demais estudos. Os conteúdos dos artigos serão analisados e os achados mais relevantes sobre o tema serão incluídos na revisão da literatura.

\section{Resultados e Discussão}

O presente estudo, inicialmente, foi localizado 643 pesquisas que aparentemente correspondia com os critérios e assim sendo selecionadas para o estudo, todavia após leitura integral, 623 foram excluídos resultando em amostra de 20 artigos. Estes que compuseram a amostra por atenderem os critérios e sendo produzidos entre 2014 até 2021. Os dados foram extraídos conforme auxílio próprio com informações de autores, ano, delineamento da pesquisa e amostra, tal como os resultados dos estudos detalhados. Assim, essas análises e sínteses dos dados foram realizadas de forma descritiva nas bases de dados já citadas. Destarte, os artigos incluídos para estudo foram identificados de A1 a A20 que abordam questões relacionadas acerca do tratamento homeopático oferecido pelo SUS, conforme mostra a distribuição completa no Quadro 1:

Quadro 1: Distribuição dos estudos incluídos na revisão integrativa de acordo com título, ano, país, delineamento, intervenção e desfecho, Teresina-PI, 2021.

\begin{tabular}{|c|c|c|c|c|c|}
\hline $\begin{array}{l}\text { Ordem } \\
\text { dos } \\
\text { artigos }\end{array}$ & Autor(es)/ ano & $\begin{array}{c}\text { Revista ou } \\
\text { periódico/ Base } \\
\text { de dados }\end{array}$ & Título & Objetivo principal da pesquisa & $\begin{array}{c}\text { Delineamento } \\
\text { da pesquisa }\end{array}$ \\
\hline A1 & $\begin{array}{l}\text { Lima, Sebastianjorge Florêncio } \\
\text { Ferreira de; Cazarin, Gisele; } \\
\text { Vanderlei, Carlos Eduardo Danzi. } \\
2019\end{array}$ & $\begin{array}{l}\text { Hist. Ciênc. } \\
\text { Saúde- } \\
\text { Manguinhos } \\
\text { SCIELO }\end{array}$ & $\begin{array}{l}\text { Homeopatia no serviço } \\
\text { público de saúde: pré- } \\
\text { avaliação das ações no } \\
\text { município do Recife (PE). }\end{array}$ & $\begin{array}{l}\text { Método de análise para identificar se seu } \\
\text { estágio de desenvolvimento permite sua } \\
\text { avaliação, e se os objetivos da intervenção } \\
\text { respondem à situação-problema. }\end{array}$ & $\begin{array}{l}\text { Método } \\
\text { qualitativo }\end{array}$ \\
\hline A2 & $\begin{array}{c}\text { Aguiar, Jordana. Aparecida Kanan, } \\
\text { Lilia. Viapiana Masiero, Anelise. } \\
2020\end{array}$ & $\begin{array}{c}\text { Rev. Saúde } \\
\text { debate vol.43 } \\
\mathrm{n}^{\circ} .123 \\
\text { SCIELO }\end{array}$ & $\begin{array}{c}\text { Práticas Integrativas e } \\
\text { Complementares na atenção } \\
\text { básica em saúde: um estudo } \\
\text { bibliométrico da produção } \\
\text { brasileira. }\end{array}$ & $\begin{array}{l}\text { Conhecer as principais características da } \\
\text { produção científica sobre PICs na atenção } \\
\text { básica em saúde desenvolvida no Brasil } \\
\text { durante os } 10 \text { primeiros anos de } \\
\text { implementação da PNPIC, além de apontar os } \\
\text { principais resultados constatados nesses } \\
\text { estudos. }\end{array}$ & $\begin{array}{l}\text { Revisão } \\
\text { Descritivo- } \\
\text { exploratório }\end{array}$ \\
\hline $\mathbf{A 3}$ & $\begin{array}{l}\text { Tesser, Charles Dalcanale; Sousa, } \\
\text { Islandia Maria Carvalho de; } \\
\text { Nascimento, Marilene Cabral do. } \\
2020\end{array}$ & $\begin{array}{l}\text { Rev. Saúde } \\
\text { debate } \\
\text { SCIELO }\end{array}$ & $\begin{array}{l}\text { Práticas Integrativas e } \\
\text { Complementares na Atenção } \\
\text { Primária à Saúde brasileira. }\end{array}$ & $\begin{array}{l}\text { Entender a situação das Práticas Integrativas e } \\
\text { Complementares (PIC) na Atenção Primária à } \\
\text { Saúde (APS) brasileira, seus problemas e } \\
\text { estratégias de enfrentamento. }\end{array}$ & $\begin{array}{c}\text { Base } \\
\text { Bibliográfica }\end{array}$ \\
\hline A4 & $\begin{array}{l}\text { Silva, João B. T. da; Carlovich } \\
\text { Filho, Jorge; Sposati, Mario C. C; } \\
\text { Cudizio Filho, } \\
\text { Oswaldo. } \\
2019\end{array}$ & $\begin{array}{c}\text { Rev. } \\
\text { Homeopatia } \\
\text { (São Paulo) } \\
\text { LILACS }\end{array}$ & $\begin{array}{l}\text { Atendimento homeopático no } \\
\text { Centro de Saúde da Barra } \\
\text { Funda, SP: uma contribuição } \\
\text { à atenção primária à saúde. }\end{array}$ & $\begin{array}{l}\text { Tem como intuito de medir a eficiência do } \\
\text { tratamento homeopático numa instituição } \\
\text { Pública. }\end{array}$ & $\begin{array}{c}\text { Revisão } \\
\text { Descritiva }\end{array}$ \\
\hline A5 & $\begin{array}{l}\text { Júnior; Emílio Telesi } \\
2016\end{array}$ & $\begin{array}{l}\text { Rev. Metrópole } \\
\text { e Saúde } \\
\text { SCIELO }\end{array}$ & $\begin{array}{c}\text { Práticas integrativas e } \\
\text { complementares em saúde, } \\
\text { uma nova eficácia para o SUS }\end{array}$ & $\begin{array}{l}\text { Compreender o uso das práticas integrativas e } \\
\text { complementares em saúde Sistema Único de } \\
\text { Saúde que merece reflexão, especialmente } \\
\text { quando se investiga o sentido de sua adoção no } \\
\text { Brasil, uma sociedade complexa que tem } \\
\text { incorporado recursos tecnológicos cada vez } \\
\text { mais sofisticados e dispendiosos. }\end{array}$ & $\begin{array}{c}\text { Base } \\
\text { Bibliográfica }\end{array}$ \\
\hline A6 & $\begin{array}{c}\text { Souza, Gustavo Henrique Castilho } \\
\text { de; Leite, Ricardo Silveira; } \\
\text { Yoshida, Edson Hideaki; } \\
\text { Santos, Nathalia Serafim dos. } \\
2019\end{array}$ & $\begin{array}{l}\text { Revista Saúde } \\
\text { em Foco } \\
\text { SCIELO }\end{array}$ & $\begin{array}{l}\text { Uso da homeopatia no } \\
\text { sistema único de saúde }\end{array}$ & $\begin{array}{l}\text { A proposta desse estudo é mostrar e avaliar a } \\
\text { frequência que a homeopatia é utilizada no } \\
\text { SUS, os fatores que envolvem a sua prescrição } \\
\text { e a capacidade de ser adotada como um } \\
\text { método confiável de tratamento. }\end{array}$ & $\begin{array}{c}\text { Revisão } \\
\text { bibliográfica }\end{array}$ \\
\hline
\end{tabular}




\begin{tabular}{|c|c|c|c|c|c|}
\hline A7 & $\begin{array}{c}\text { Ruela, Ludmila de Oliveira; } \\
\text { Caroline de Castro Moura; Clícia } \\
\text { Valim Côrtes Gradim; Juliana } \\
\text { Stefanello; Denise Hollanda Iunes; } \\
\text { Rogério Ramos do Prado } \\
2019 \\
\end{array}$ & $\begin{array}{l}\text { Ciênc. saúde } \\
\text { coletiva } \\
\text { SCIELO }\end{array}$ & $\begin{array}{l}\text { Implementação, acesso e uso } \\
\text { das práticas integrativas e } \\
\text { complementares no Sistema } \\
\text { Único de Saúde: revisão da } \\
\text { literatura }\end{array}$ & $\begin{array}{l}\text { O objetivo deste estudo foi analisar a } \\
\text { implementação, o acesso e o uso das PIC no } \\
\text { Sistema Único de Saúde (SUS) após a } \\
\text { implantação da política. }\end{array}$ & $\begin{array}{l}\text { Revisão } \\
\text { integrativa da } \\
\text { literatura }\end{array}$ \\
\hline A8 & $\begin{array}{c}\text { Cabo, Domingos José Vaz } \\
2014\end{array}$ & $\begin{array}{l}\text { FIOCRUZ } \\
\text { LILACS }\end{array}$ & $\begin{array}{c}\text { Homeopatia na Estratégia } \\
\text { Saúde da Família: apoio } \\
\text { matricial e visão sistêmica } \\
\text { cartografando a integralidade } \\
\text { do cuidado }\end{array}$ & $\begin{array}{l}\text { Analisar os limites e possibilidades da atuação } \\
\text { do homeopata na Estratégia Saúde da Família. }\end{array}$ & $\begin{array}{l}\text { Estudo } \\
\text { qualitativo }\end{array}$ \\
\hline A9 & $\begin{array}{c}\text { Schwarz, Aline; Pacheco, Fabio } \\
\text { Kovacevik; Ramos, Roberta Fiuza. } \\
2014\end{array}$ & $\begin{array}{l}\text { T. São Paulo } \\
\text { LILACS }\end{array}$ & $\begin{array}{l}\text { Homeopatia no Sistema } \\
\text { Único de Saúde }\end{array}$ & $\begin{array}{l}\text { Visa retratar o atendimento homeopático, o } \\
\text { perfil do paciente, as formas medicamentosas } \\
\text { mais receitadas, o grau de abandono do } \\
\text { tratamento, a duração do tratamento e forma de } \\
\text { aquisição dos medicamentos pelos pacientes } \\
\text { atendidos em ambulatórios do SUS do Estado } \\
\text { de São Paulo. }\end{array}$ & $\begin{array}{l}\text { Estudo } \\
\text { qualitativo }\end{array}$ \\
\hline A10 & $\begin{array}{l}\text { Lima, Felipette; } \text { et al. } \\
2015\end{array}$ & $\begin{array}{c}\text { Rev. Av. } \\
\text { enfermagem } \\
\text { LILACS }\end{array}$ & $\begin{array}{c}\text { Uso de terapias integrativas e } \\
\text { complementares por pacientes } \\
\text { em quimioterapia }\end{array}$ & $\begin{array}{l}\text { Conhecer as terapias integrativas e } \\
\text { complementares utilizadas pelos pacientes em } \\
\text { quimioterapia oncológica no SUS. }\end{array}$ & $\begin{array}{l}\text { Estudo } \\
\text { qualitativo }\end{array}$ \\
\hline A11 & $\begin{array}{l}\text { Mendes, Dayana Senger; } \text { et al. } \\
2019\end{array}$ & $\begin{array}{l}\text { Journal Health } \\
\text { NPEPS } \\
\text { LILACS } \\
\end{array}$ & $\begin{array}{c}\text { Benefícios das práticas } \\
\text { integrativas e complementares } \\
\text { no cuidado de enfermagem }\end{array}$ & $\begin{array}{l}\text { Caracterizar os benefícios das práticas } \\
\text { integrativas e complementares no cuidado de } \\
\text { enfermagem no SUS. }\end{array}$ & $\begin{array}{l}\text { Revisão } \\
\text { integrativa }\end{array}$ \\
\hline $\mathbf{A 1 2}$ & $\begin{array}{l}\text { Melo, Pamela Santos de; Ito, } \\
\text { Rosilene } \\
2017\end{array}$ & $\begin{array}{c}\text { Revista saúde - } \\
\text { ung-ser } \\
\text { LILACS }\end{array}$ & $\begin{array}{l}\text { Homeopatia: dificuldades e } \\
\text { benefícios da implantação no } \\
\text { sistema único de saúde e a } \\
\text { importância da política } \\
\text { nacional das práticas } \\
\text { integrativas e complementares } \\
\text { (PNPIC) } \\
\end{array}$ & $\begin{array}{l}\text { Analisar a homeopatia nas Unidades Básicas } \\
\text { de Saúde (UBS) e sua aceitação pelos gestores } \\
\text { e usuários. }\end{array}$ & $\begin{array}{l}\text { Revisão da } \\
\text { literatura }\end{array}$ \\
\hline A13 & $\begin{array}{l}\text { Dias, Janaina de Sousa; Melo, } \\
\text { Angelita Cristine de; Silva, Eduardo } \\
\text { Sergio da. } \\
2014 \\
\end{array}$ & $\begin{array}{l}\text { Espaç. Saúde } \\
\text { (Online) } \\
\text { LILACS }\end{array}$ & $\begin{array}{l}\text { Homeopatia: percepção da } \\
\text { população sobre significado, } \\
\text { acesso, utilização e } \\
\text { implantação no SUS }\end{array}$ & $\begin{array}{l}\text { Verificar o conhecimento dos usuários do SUS } \\
\text { sobre a homeopatia e o seu interesse pela } \\
\text { implantação da prática em Divinópolis, MG. }\end{array}$ & $\begin{array}{l}\text { Estudo } \\
\text { qualitativo }\end{array}$ \\
\hline A14 & $\begin{array}{c}\text { Chaves, Vera L. de Vasconcelos; } \\
\text { Vasconcelos, Ana L. R; Sampaio, } \\
\text { Aletheia S; Vanderlei, Carlos E. D; } \\
\text { Melo, Maria F.R.B. de. } \\
2019 \\
\end{array}$ & $\begin{array}{c}\text { Rev. } \\
\text { Homeopatia } \\
\text { (Säo Paulo) } \\
\text { LILACS } \\
\end{array}$ & $\begin{array}{l}\text { Resposta clínica e } \\
\text { imunológica ao tratamento } \\
\text { homeopático em portador de } \\
\text { HIV: relato de caso }\end{array}$ & $\begin{array}{l}\text { Avaliar os resultados do tratamento } \\
\text { homeopático em um grupo de } 28 \text { pacientes } \\
\text { soropositivos para o vírus HIV, usuários da } \\
\text { Unidade Integrada de Saúde de Taubaté (SP). }\end{array}$ & Relato de caso \\
\hline A15 & $\begin{array}{l}\text { Teixeira, Marcus Zulian. } \\
2019\end{array}$ & $\begin{array}{c}\text { Diagn } \\
\text { Tratamento } \\
\text { LILACS }\end{array}$ & $\begin{array}{l}\text { Homeopatia: o que os } \\
\text { médicos precisam saber sobre } \\
\text { esta especialidade médica }\end{array}$ & $\begin{array}{l}\text { O objetivo deste artigo é descrever os } \\
\text { princípios do tratamento homeopático e } \\
\text { discutir as evidências científicas que os } \\
\text { fundamentam. }\end{array}$ & $\begin{array}{l}\text { Revisão } \\
\text { narrativa }\end{array}$ \\
\hline A16 & $\begin{array}{l}\text { Nunes, Laila A. de Souza; Abrahão, } \\
\text { Fabiana. } \\
2016\end{array}$ & $\begin{array}{c}\text { Rev. } \\
\text { Homeopatia } \\
\text { (Säo Paulo) } \\
\text { LILACS }\end{array}$ & $\begin{array}{l}\text { A homeopatia como a arte de } \\
\text { cuidar em saúde: análise da } \\
\text { percepção dos usuários do } \\
\text { SUS sobre o trabalho de } \\
\text { homeopatia na cidade de } \\
\text { Macaé/RJ } \\
\end{array}$ & $\begin{array}{l}\text { O objetivo do presente estudo foi investigar a } \\
\text { percepção dos usuários quanto ao trabalho de } \\
\text { Homeopatia contra a Dengue, realizado no } \\
\text { município de Macaé-RJ para subsidiar a } \\
\text { elaboração de um folder a ser utilizado como } \\
\text { meio de divulgação científica. }\end{array}$ & $\begin{array}{l}\text { Abordagem } \\
\text { quali- } \\
\text { quantitativa }\end{array}$ \\
\hline $\mathbf{A 1 7}$ & $\begin{array}{c}\text { Amorim, Andresa Mara Reis; et al. } \\
2019\end{array}$ & $\begin{array}{l}\text { Brazilian } \\
\text { Journal of } \\
\text { Surgery and } \\
\text { Clinical } \\
\text { Research - } \\
\text { BJSCR } \\
\text { PUBMED } \\
\end{array}$ & $\begin{array}{l}\text { O uso da homeopatia por } \\
\text { gestantes, lactantes e lactentes }\end{array}$ & $\begin{array}{l}\text { Tem como objetivo compilar informações } \\
\text { sobre a terapia homeopática utilizada em } \\
\text { gestantes, lactantes e lactentes no SUS, } \\
\text { reunindo informações quanto ao benefício, } \\
\text { apresentado os resultados obtidos por meio de } \\
\text { revisões bibliográficas. }\end{array}$ & $\begin{array}{l}\text { Revisão de } \\
\text { literatura }\end{array}$ \\
\hline A18 & $\begin{array}{l}\text { Toniol, Rodrigo Ferreira } \\
2015\end{array}$ & $\begin{array}{l}\text { UFRGS - } \\
\text { Repositório } \\
\text { Digital } \\
\text { PUBMED }\end{array}$ & $\begin{array}{c}\text { Do espírito na saúde: oferta e } \\
\text { uso de terapias } \\
\text { alternativas/complementares } \\
\text { nos serviços de saúde pública } \\
\text { no Brasil } \\
\end{array}$ & $\begin{array}{l}\text { Analisar o processo de invenção das Práticas } \\
\text { Integrativas e Complementares (PICs). }\end{array}$ & $\begin{array}{c}\text { Revisão } \\
\text { bibliográfica }\end{array}$ \\
\hline A19 & $\begin{array}{c}\text { Silva, Ana Laura Pereira; Sobral, } \\
\text { Jennifer Hellen Melo; Campelo, } \\
\text { Juliana Marina; Neco, Heytor } \\
\text { Victor Pereira da Costa. } \\
2021 \\
\end{array}$ & $\begin{array}{l}\text { Rev. } \\
\text { SUSTINERE } \\
\text { PUBMED }\end{array}$ & $\begin{array}{l}\text { Percepções sobre homeopatia } \\
\text { na perspectiva de discentes } \\
\text { dos cursos de saúde de um } \\
\text { centro universitário de } \\
\text { Recife-PE } \\
\end{array}$ & $\begin{array}{l}\text { O objetivo deste estudo foi descrever as } \\
\text { percepções sobre homeopatia na perspectiva } \\
\text { dos discentes da área de saúde de um centro } \\
\text { universitário público na cidade de Recife-PE }\end{array}$ & $\begin{array}{l}\text { Estudo } \\
\text { descritivo e } \\
\text { quantitativo }\end{array}$ \\
\hline $\mathbf{A 2 0}$ & $\begin{array}{c}\text { Silva, Aline de Oliveira Galvão; } \\
\text { Andrade, Leonardo Guimarães; } \\
\text { Silva, Michel Santos; Pugliese, } \\
\text { Fabiana Sousa } \\
2021 \\
\end{array}$ & $\begin{array}{c}\text { Revista REASE } \\
\text { PUBMED }\end{array}$ & $\begin{array}{l}\text { Tratamento homeopático e } \\
\text { sua implantação no SUS }\end{array}$ & $\begin{array}{l}\text { O objetivo deste estudo foi compreender sobre } \\
\text { a Homeopatia e seu desenvolvimento, tal como } \\
\text { o incentivo da OMS acerca do assunto }\end{array}$ & $\begin{array}{c}\text { Revisão } \\
\text { bibliográfica }\end{array}$ \\
\hline
\end{tabular}

Fonte: Autores (2021). 
Foram identificadas publicações dos anos de 2021(10\%), 2020(10\%), 2019(40\%), 2017(5\%), 2016(10\%), 2015(10\%) e 2014(15\%). Sendo a maioria dos estudos desenvolvidos em pesquisas bibliográficas. No Quadro 2, encontra-se a descrição do processo acerca dos principais resultados e conclusão do que se é abordado nos artigos selecionados para estudo.

Quadro 2: Distribuição acerca dos estudos incluídos na revisão integrativa de acordo com os principais resultados e conclusão da investigação, Teresina-PI, 2021.

\begin{tabular}{|c|c|c|}
\hline $\begin{array}{l}\text { Ordem dos } \\
\text { artigos }\end{array}$ & Principais resultados & Conclusão da investigação \\
\hline A1 & $\begin{array}{l}\text { Apontou a necessidade de atualização das normas vigentes em relação } \\
\text { à PMPIC, uma vez que essas deveriam incorporar a suas diretrizes as } \\
\text { mudanças ocorridas no modelo de atenção à saúde municipal. } \\
\text { Deveriam também definir e delimitar as PICs que compõem as normas } \\
\text { vigentes e seus respectivos protocolos e fluxos na rede de saúde. }\end{array}$ & $\begin{array}{l}\text { Sua construção, de maneira participativa, contribuiu para o } \\
\text { monitoramento do progresso de uma dada intervenção ao } \\
\text { fornecer um plano claro de acompanhamento. }\end{array}$ \\
\hline A2 & $\begin{array}{l}\text { Identificou-se em pesquisa que a maior parte dos gestores e dos } \\
\text { profissionais de saúde não conhecia a PNPIC. Por sua vez, os } \\
\text { profissionais que a conheciam a utilizavam para disseminar e justificar } \\
\text { a utilização de homeopatia. }\end{array}$ & $\begin{array}{l}\text { Considera-se que profissionais e usuários buscam nas PICs } \\
\text { possibilidades de melhoria da saúde e da qualidade de vida. }\end{array}$ \\
\hline $\mathbf{A 3}$ & $\begin{array}{l}\text { O levantamento foi feito considerando-se a primeira consulta } \\
\text { homeopática ou a consulta que motivou o encaminhamento à } \\
\text { homeopatia, para tentar averiguar o perfil patológico de tais clientes. }\end{array}$ & $\begin{array}{l}\text { O atendimento homeopático iniciou-se de modo não sistemático } \\
\text { e sem agendamento e, quando iniciou o agendamento, este foi } \\
\text { muitas vezes impossível de ser evidenciado. }\end{array}$ \\
\hline $\mathbf{A 4}$ & $\begin{array}{l}\text { Os projetos investigaram as seguintes PIC: acupuntura (26\%), } \\
\text { fitoterapia }(21 \%) \text {, auriculoterapia }(10 \%) \text {, medicina antroposófica }(4 \%) \text {, } \\
\text { homeopatia }(2 \%) \text {, meditação }(2 \%) \text {, investigação de mais de uma PIC } \\
(16 \%) \text {; e } 19 \% \text { não especificaram nenhuma PIC. }\end{array}$ & $\begin{array}{l}\text { De forma dispersa, profissionais da ESF têm sido os } \\
\text { protagonistas das PIC no SUS. Isso indica que elas devem estar } \\
\text { trazendo efetividade à sua prática, visto que eles têm investido } \\
\text { tempo e recursos em formação e depois no exercício das PIC. }\end{array}$ \\
\hline A5 & $\begin{array}{l}\text { Percebe-se que o avanço das medicinas tradicionais nos países } \\
\text { ocidentais tem criado condições para favorecer a troca entre as duas } \\
\text { correntes de pensamento. É interessante realçar que uma das práticas } \\
\text { que caracterizam a complexidade dos problemas sociais, em especial } \\
\text { no campo da saúde pública, é o enfoque interdisciplinar das pesquisas } \\
\text { científicas e tecnológicas. Pode-se constatar que a pesquisa de caráter } \\
\text { interdisciplinar vem ganhando espaço no campo da saúde pública. }\end{array}$ & $\begin{array}{l}\text { Não é por necessidade de saúde que milhares de pessoas vêm } \\
\text { procurando as Práticas como forma de recuperação da saúde. } \\
\text { Afinal, temos o que há de mais moderno e avançado na } \\
\text { medicina, tanto no SUS como no sistema privado. Não é por } \\
\text { falta de procedimentos diagnósticos, médicos, medicamentos ou } \\
\text { outros recursos que estamos resgatando o valor das medicinas } \\
\text { tradicionais. É por vontade de afirmar uma identidade de } \\
\text { cuidado oposta à prática de cuidado feita de forma muitas vezes } \\
\text { desumana, que infelizmente prepondera entre nós. }\end{array}$ \\
\hline A6 & $\begin{array}{l}\text { Como principais resultados destacam-se: a posição dos profissionais da } \\
\text { saúde em relação ao uso da homeopatia; posição dos usuários em } \\
\text { relação ao uso da homeopatia e custos em relação ao uso da } \\
\text { homeopatia. }\end{array}$ & $\begin{array}{l}\text { A proposta da inserção e reconhecimento da homeopatia no SUS } \\
\text { é um tema que merece atenção. Além do fato de ter um custo- } \\
\text { benefício de fácil acesso a população, é uma terapia que } \\
\text { demonstra eficácia, segurança e é capaz de tratar o paciente com } \\
\text { individualidade. Diante dos estudos analisados, a homeopatia se } \\
\text { mostrou capaz de atender todos os requisitos para ter seu espaço } \\
\text { dentro sistema público de saúde. }\end{array}$ \\
\hline A7 & $\begin{array}{l}\text { Os temas mais abordados entre a pesquisa realizada foram: as } \\
\text { principais PIC adotadas no SUS, o acesso a essas práticas, e o preparo } \\
\text { dos serviços e dos profissionais da saúde para a implementação e } \\
\text { utilização das mesmas. A partir desses temas, foram elaboradas as } \\
\text { categorias de discussão. }\end{array}$ & $\begin{array}{l}\text { Considera-se, após uma década de implantação da política, que } \\
\text { as PIC são oferecidas de forma incipiente no SUS e a escassez } \\
\text { de dados sobre determinadas práticas mostram-se como uma } \\
\text { limitação sobre o atual cenário dessa abordagem. Entretanto, é } \\
\text { possível observar reflexos positivos para os usuários e para os } \\
\text { serviços que aderiram à sua utilização, mesmo que ainda existam } \\
\text { desafios em sua implementação, no seu acesso, no seu uso e na } \\
\text { formação de profissionais capacitados. }\end{array}$ \\
\hline A8 & $\begin{array}{l}\text { Os resultados sugerem que a presença da homeopatia e demais práticas } \\
\text { integrativas no cotidiano da atenção primária, a partir do exercício e do } \\
\text { compartilhamento do cuidado através do apoio matricial, define um } \\
\text { novo paradigma, que contempla o sujeito a partir da complexidade de } \\
\text { suas determinações, impactando na resolutividade e na humanização do } \\
\text { atendimento. }\end{array}$ & $\begin{array}{l}\text { Olhar para esta rede de relações pela ótica da homeopatia e } \\
\text { daqueles que a exercem desde os primórdios do Sistema Único } \\
\text { de Saúde não proporciona somente discutir o papel das Práticas } \\
\text { Integrativas frente à Atenção Primária. (...) Assim, a pesquisa } \\
\text { teve o papel fundamental para o reconhecimento destas práticas, } \\
\text { configuradas mais tarde como políticas públicas. }\end{array}$ \\
\hline A9 & $\begin{array}{l}\text { Todos os pacientes entrevistados na cidade de São Paulo disseram } \\
\text { acreditar na Homeopatia. Já na região de Botucatu, 28,6\% dos } \\
\text { pacientes entrevistados disseram não acreditar na Homeopatia, } \\
\text { possivelmente pelo fato de apenas } 52 \% \text { destes terem utilizado a } \\
\text { Homeopatia. Além disso, apenas } 43 \% \text { dos entrevistados em Botucatu } \\
\text { foram atendidos pelo SUS, enquanto } 75 \% \text { dos pacientes entrevistados } \\
\text { em São Paulo foram atendidos pelo sistema privado. }\end{array}$ & $\begin{array}{l}\text { Adicionalmente, enquanto } 100 \% \text { dos pacientes entrevistados em } \\
\text { São Paulo disseram utilizar e recomendar a Homeopatia, apenas } \\
57 \% \text { dois entrevistados em Botucatu disseram recomendar o } \\
\text { tratamento e apenas } 48 \% \text { disseram empregar a Homeopatia para } \\
\text { o tratamento de enfermidades (...). De um modo geral, é } \\
\text { importante que a equipe homeopática do SUS de São Paulo e } \\
\text { Botucatu se empenhem em esclarecer as dúvidas dos pacientes } \\
\text { quanto ao conceito da Homeopatia e em adquirir recursos para } \\
\text { que o medicamento homeopático seja oferecido gratuitamente ao } \\
\text { paciente. }\end{array}$ \\
\hline A10 & $\begin{array}{l}\text { As terapias apontadas neste estudo foram a homeopatia, a fitoterapia e } \\
\text { as plantas medicinais e percebeu-se que elas aumentam a sensação de } \\
\text { bem-estar, possibilitam o estabelecimento de vínculos positivos com } \\
\text { profissionais da saúde, e fazem parte do saber popular e estão } \\
\text { interligadas ao conhecimento científico. }\end{array}$ & $\begin{array}{l}\text { Apreende-se que uso de terapias integrativas e complementares } \\
\text { em oncologia permite a aproximação do profissional enfermeiro } \\
\text { com o paciente em quimioterapia, conhecendo-o em sua } \\
\text { complexidade, principalmente no SUS. }\end{array}$ \\
\hline A11 & $\begin{array}{l}\text { Entre os benefícios das práticas integrativas foi evidenciado o } \\
\text { relaxamento e bem-estar, alívio da dor e da ansiedade, diminuição de }\end{array}$ & $\begin{array}{l}\text { É preciso protagonismo, empoderamento e preparo da } \\
\text { enfermagem para a implementação das PICs em sua prática }\end{array}$ \\
\hline
\end{tabular}




\begin{tabular}{|c|c|c|}
\hline & $\begin{array}{l}\text { sinais e sintomas de doenças, estimula o contato profissional-paciente, } \\
\text { redução do uso de medicamentos, fortalecimento do sistema } \\
\text { imunológico, melhoria da qualidade de vida e diminuição de reações } \\
\text { adversas. }\end{array}$ & $\begin{array}{l}\text { diária qualificando as práticas assistenciais e reduzindo os custos } \\
\text { hospitalares. }\end{array}$ \\
\hline A12 & $\begin{array}{l}\text { Foi observado após cinco anos da implantação da PNPIC, em 2011, } \\
\text { correspondeu ao período que houve mais publicações sobre o assunto } \\
\text { na BVS e em relação à Pubmed, foram nos últimos } 3 \text { anos em que } \\
\text { houve crescimento em publicações sobre o assunto. }\end{array}$ & $\begin{array}{l}\text { Os tratamentos alternativos, como a homeopatia, através da } \\
\text { PNPIC, permitem que a população tenha acesso à homeopatia, } \\
\text { acupuntura e fitoterapia, percebe-se pelas publicações em } \\
\text { revistas técnicas da área, cujo critério de inserção e/ou exclusão } \\
\text { destas publicações para análise foram a aceitação do usuário do } \\
\text { SUS ao tratamento homeopático e sua implantação pelos } \\
\text { gestores das unidades. }\end{array}$ \\
\hline $\mathbf{A 1 3}$ & $\begin{array}{l}\text { Prevalece na população pouco ou nenhum conhecimento sobre a } \\
\text { homeopatia. No imaginário dos entrevistados constatou-se a confusão } \\
\text { de homeopatia e tratamentos fitoterápicos caseiros; identificação de } \\
\text { homeopatia como doença; a crença de inocuidade ao organismo dos } \\
\text { medicamentos homeopáticos ou fitoterápicos e a relação de fé ou } \\
\text { misticismo com os homeopáticos ou fitoterápicos. Apesar do pouco } \\
\text { conhecimento, a maioria dos entrevistados considera importante a } \\
\text { implantação do tratamento homeopático no SUS Divinópolis como } \\
\text { uma alternativa de assistência. }\end{array}$ & $\begin{array}{l}\text { Existe interesse na implantação da homeopatia no SUS } \\
\text { Divinópolis. Recomenda-se aqui a realização de novos estudos } \\
\text { que busquem maior amplitude de resultados. }\end{array}$ \\
\hline A14 & $\begin{array}{l}\text { Resultados são compatíveis com os relatados por Silva, em pesquisa } \\
\text { clínica com o objetivo de avaliar os resultados do tratamento } \\
\text { homeopático em um grupo de } 28 \text { pacientes soropositivos para o vírus } \\
\text { HIV, usuários da Unidade Integrada de Saúde de Taubaté (SP). Neste } \\
\text { trabalho foi possível observar que um grupo de pacientes apresentou } \\
\text { boa evolução clínica e emocional e as contagens sucessivas de } \\
\text { linfócitos CD4+e da relação CD4+/ CD8+ mostraram uma tendência } \\
\text { de estabilização ou aumento. }\end{array}$ & $\begin{array}{l}\text { O caso ora apresentado corrobora a viabilidade da terapêutica } \\
\text { homeopática como adjuvante para portadores do HIV. Contudo, } \\
\text { faz-se necessário um incremento no estudo de outros casos, e a } \\
\text { realização de pesquisas do tipo ensaio clínico, randomizado e } \\
\text { duplo-cego, a fim de comprovar definitivamente a eficácia do } \\
\text { tratamento homeopático. Também podemos concluir que a } \\
\text { omissão do atendimento homeopático no serviço público } \\
\text { contribuiu à consequente piora das condições imunológicas da } \\
\text { paciente, evento que robustece nossos achados, no que diz } \\
\text { respeito à boa resposta ao tratamento instituído. }\end{array}$ \\
\hline A15 & 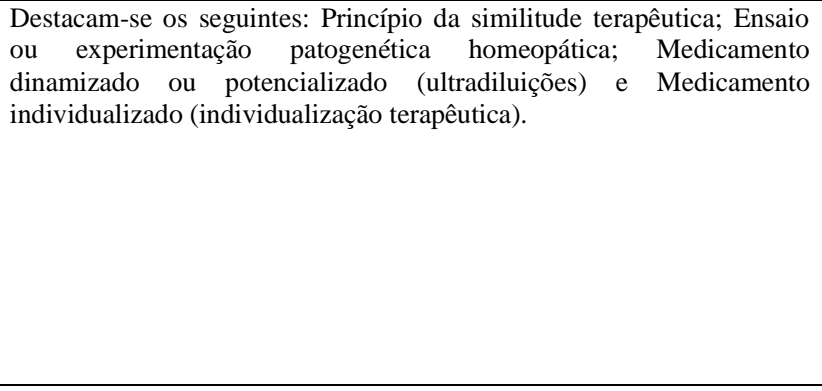 & $\begin{array}{l}\text { Após } 220 \text { anos do início de sua aplicação terapêutica, } \\
\text { colaborando com o aumento da resolutividade em diversas } \\
\text { classes de doenças crônicas, a homeopatia permanece } \\
\text { marginalizada pelo conhecimento científico ortodoxo, por se } \\
\text { fundamentar em princípios distintos da prática médica } \\
\text { convencional. Com o intuito de esclarecer os colegas médicos a } \\
\text { respeito das peculiaridades do modelo homeopático, é discorrido } \\
\text { ainda sobre os aspectos filosóficos, clínicos e científicos que } \\
\text { norteiam a boa prática homeopática, trazendo-lhes subsídios } \\
\text { mínimos para avaliar eventuais tratamentos homeopáticos a que } \\
\text { seus pacientes estejam submetidos, assim como informá-los } \\
\text { sobre uma alternativa terapêutica de grande valia e aplicação. }\end{array}$ \\
\hline A16 & $\begin{array}{l}\text { A maioria dos entrevistados considera importante o trabalho de } \\
\text { educação popular em saúde sobre o tratamento homeopático na rede } \\
\text { pública de saúde, a fim de conhecerem melhor essa alternativa de } \\
\text { assistência que o SUS de Macaé oferece à população. Nesse processo, } \\
\text { o usuário entra como um agente de mudança, pois foi aberto um espaço } \\
\text { coletivo para manifestar os seus interesses em relação à homeopatia. } \\
\text { Tais interesses são produtos subjetivos relevantes, pois advêm das } \\
\text { percepçães dos usuários e foram a base para a construção de um folder, } \\
\text { produto final do trabalho, que possivelmente trara para eles novos } \\
\text { conhecimentos sobre a homeopatia. }\end{array}$ & $\begin{array}{l}\text { O conhecimento da percepção do usuário sobre o tratamento } \\
\text { homeopático sob o ponto de vista deste tipo atenção, em que o } \\
\text { indivíduo é o centro do cuidado em saúde, permite ousar supor } \\
\text { que a ciência homeopática vai além de ser a verdadeira arte de } \\
\text { curar, para ser também, a verdadeira arte do cuidar, em saúde. }\end{array}$ \\
\hline A17 & $\begin{array}{l}\text { No Sistema Único de Saúde a aceitação da homeopatia começou a } \\
\text { partir de } 1998 \text {, após certificação que tinham médicos que realizavam } \\
\text { atendimentos em certos municípios no Brasil, possibilitando assim, nas } \\
\text { unidades básicas de saúde a prática da homeopatia. A homeopatia vem } \\
\text { sendo citada como tratamento seguro para grávidas, lactantes e } \\
\text { lactantes por órgãos governamentais, como a secretaria do Estado de } \\
\text { Saúde do Distrito Federal e Ministério da Saúde, em } 2014 \text {. }\end{array}$ & $\begin{array}{l}\text { A homeopatia vem sendo utilizada como alternativa } \\
\text { complementar efetiva e segura, atuando de forma preventiva e } \\
\text { curativa no tratamento de diversas patologias. Sua indicação } \\
\text { compreende o ser humano na sua totalidade e de forma holística } \\
\text { e não uma doença específica. Atua no organismo promovendo o } \\
\text { equilíbrio humano em todos os aspectos atuando nos planos } \\
\text { físico, mental e emocional, melhorando assim, o sistema } \\
\text { imunitário e reestabelecendo a força vital, tratando assim o } \\
\text { indivíduo como um todo e não apenas a doença local. }\end{array}$ \\
\hline A18 & $\begin{array}{l}\text { As PICs refere-se tanto a produção de registros burocráticos estatais } \\
\text { específicos para essas práticas, como também indica o trabalho } \\
\text { cotidiano de terapeutas, médicos e gestores empenhados em fazer com } \\
\text { que terapias alternativas/complementares possam ser convertidas em } \\
\text { PICs. }\end{array}$ & $\begin{array}{l}\text { Argumenta-se pela necessidade de atenção à categoria } \\
\text { espiritualidade em si, ainda assim o autor demonstra como a } \\
\text { "espiritualidade" tem sido capaz de mobilizar agentes e } \\
\text { instituições implicadas na oferta de terapias } \\
\text { alternativas/complementares no SUS. Sugere-se, por fim, que a } \\
\text { oferta de PICs no SUS tem se constituído como uma modalidade } \\
\text { oficial de atenção à dimensão espiritual da saúde no Brasil. }\end{array}$ \\
\hline A19 & $\begin{array}{l}\text { Apesar de } 65,2 \% \text { dos discentes relatarem ter ouvido falar sobre } \\
\text { homeopatia, } 73 \% \text { declararam ter pouco ou nenhum conhecimento sobre } \\
\text { as formas de tratamento. Além disso, } 82,8 \% \text { dos discentes afirmaram } \\
\text { não conhecer as PNPIC (Política Nacional de Práticas Integrativas e } \\
\text { Complementares no SUS), e nem saber que medicamentos } \\
\text { homeopáticos são distribuídos gratuitamente pelo SUS }(86 \%) \text {. Existe } \\
\text { interesse dos estudantes de saúde em incluir homeopatia como } \\
\text { disciplina na grade de seus cursos, a fim de estarem aptos para oferecer } \\
\text { um atendimento integral aos pacientes. }\end{array}$ & $\begin{array}{l}\text { Portanto, há necessidade de instituições de ensino superior } \\
\text { investirem e promoverem disciplinas que abordem a homeopatia, } \\
\text { para formarem profissionais com maior conhecimento sobre as } \\
\text { PIC, o que irá acarretar maior informação para a população, } \\
\text { contribuindo na melhoria da saúde individual e coletiva através } \\
\text { da saúde pública. }\end{array}$ \\
\hline
\end{tabular}




\begin{tabular}{|c|c|c|}
\hline A20 & $\begin{array}{l}\text { Após estudo, foi possível entender que entre as principais doenças } \\
\text { tratadas com a homeopatia destacam-se: os problemas psicológicos que } \\
\text { auxilia no tratamento de transtornos psicológicos; os problemas de peso } \\
\text { que apesar de não trabalhar de forma direta na perda de peso, mas nas } \\
\text { disfunções que provocam o sobrepeso; problemas respiratórios que } \\
\text { podem ter os efeitos reduzidos como é o caso da rinite e sinusite. }\end{array}$ & $\begin{array}{l}\text { A proposta de inserção e identificação da homeopatia no SUS é } \\
\text { um tema, digno de atenção. Além de tornar mais fácil para as } \\
\text { pessoas obterem uma boa relação custo-benefício, também é } \\
\text { comprovada a eficácia, segurança e capacidade de personalizar o } \\
\text { tratamento dos pacientes. Tendo em vista as pesquisas } \\
\text { analisadas, a homeopatia pode atender a todos os requisitos e ter } \\
\text { um lugar no sistema público de saúde. Os profissionais de saúde } \\
\text { são importantes para mudar esse status da procura tão pequena } \\
\text { pelo tratamento homeopático, pois esses são os mais } \\
\text { responsáveis devido à falta de divulgação da importância da } \\
\text { homeopatia para a sociedade. }\end{array}$ \\
\hline
\end{tabular}

Fonte: Autores (2021).

As leituras dos artigos selecionados para estudo possibilitaram compreender que estes abordam as seguintes temáticas: I - Necessidade de atenção à construção da Política Municipal de Práticas Integrativas e Complementares; uma vez que esta faz parte do sistema de saúde pública brasileira há mais de uma década e possibilitou ao SUS a prática da homeopatia. II - Pouca atenção com a homeopatia, pois a maior parte dos usuários conhece pouco sobre o assunto e destaca sua similaridade às práticas populares e religiosas devido à falta de informações sobre os procedimentos e que a medicina não oferece explicação farmacológica para a ação das substâncias.

No que se refere aos itens em destaque, todos os artigos estudados (A1-A20) destacam a importância da atenção a homeopatia, sobretudo, no SUS como necessidade de alternativa de assistência. Ainda assim, esta pode estar associada à falta de conhecimento por parte dos profissionais da área, é o que destaca os autores Aguiar et al. (2020) (A2); Júnior (2016) (A5); Souza et al. (2019) ${ }^{(\mathrm{A} 6)}$ e Melo; Ito (2017) ${ }^{\text {(A12) }}$ em seus estudos, bem como a homeopatia se mostra capaz de atender todos os requisitos para ter seu espaço dentro sistema público de saúde. Conforme Silva et al. (2021) ${ }^{(A 19)}$ a maioria dos discentes não têm ou possuem poucas informações sobre a homeopatia, por sua vez, Dias et al. (2014) ${ }^{(A 13)}$ traz em seu estudo o não conhecimento por parte da população. Além disso, Lima et al. $(2019)^{(\mathrm{Al})}$ explicita que se deve atualizar as normas em relação as PICs.

Isso posto, os autores Silva et al. (2019) (A4) ainda abordam em sua pesquisa que os profissionais envolvidos na Estratégia de Saúde da Família são protagonistas dessas PICs no SUS, tal como os autores Teixeira (2019) (A15) e Nunes et al. (2016) ${ }^{(A 16)}$ evidenciam estas sendo de grande valor e que o tratamento homeopático se trata de uma verdadeira arte de curar. Em contradição, Ruela et al. (2019) (A7) e Mendes et al. (2019) (A11) salientam que o acesso a essas práticas e o preparo dos serviços e dos profissionais da saúde são de total escassez, bem como necessitam de protagonistas.

Entende-se que as práticas complementares e integrativas trazem benefícios e relaxamento para o paciente, visto que supera o tratamento a base de medicamentos, conforme o estudo de Mendes et al. (2019) (A11), essas práticas possibilitam um "tratamento livre de efeitos colaterais" e trazem benefícios como: bem-estar, alívio das dores e ansiedade, Silva et al. (2021)

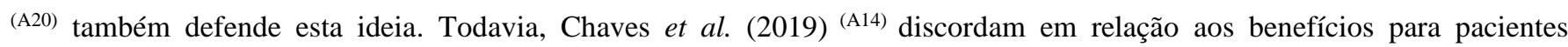
portadores de HIV, pois há registros de piora nas condições imunológicas. Em complemento, o estudo feito por Melo; Ito (2017) ${ }^{(\mathrm{A} 12)}$ e Amorim et al. (2019) ${ }^{\text {(A17) }}$ acentuam sobre a aceitação dos pacientes ao tratamento de homeopatia e acreditam na prática da homeopatia e demais PICs.

Destarte, o presente estudo feito pelos artigos escolhidos demonstra que é imprescindível as práticas integrativas e complementares, principalmente a homeopatia, pois é bastante indicada nos diversos tipos de doenças e transtornos de saúde e vai além da verdadeira arte de curar.

\section{Considerações Finais}

A homeopatia permeia na área da saúde há mais de 200 anos e que tende a contribuir no melhoramento de uma assistência já efetiva no sentido de promoção de saúde e qualidade de vida. É importante ressaltar sobre a importância de 
abordar as práticas nas graduações na área da saúde, de forma que os profissionais recém-formados já adentrem a prática profissional inteirados dessas abordagens e sua aplicabilidade, no Brasil, por exemplo, apenas algumas universidades federais ofertam disciplinas eletivas de homeopatia nos cursos de Medicina.

De acordo com os resultados obtidos no presente estudo, foi possível concluir que ainda existe uma escassez de publicações que abordam sobre o tratamento homeopático oferecido pelo SUS. Ainda assim, a prática de cuidado é de fundamental importância para a qualificação de tais ações, assim como no cuidado integral à saúde e significativo para desenvolver os conhecimentos acerca da análise e da possibilidade de buscar compreender mais sobre o assunto mesmo revelando que ainda é pouco explorado.

\section{Referências}

Aguiar, J., Kanan, L. A., \& Masiero, A. V. (2019). Práticas Integrativas e Complementares na atenção básica em saúde: um estudo bibliométrico da produção brasileira. Saúde debate.43(123).

Amorim, A. M. R., et al. (2019). O uso da homeopatia por gestantes, lactantes e lactentes.27(1), (154-158).

Brasil (2006). Portaria 971/2006. Ministério da Saúde. Política Nacional de Práticas Integrativas e Complementares. (2006). http://bvsms.saude.gov.br/bvs/saudelegis/gm/2006/prt0971_03_05_2006.ht ml.

Cabo, D. J. V. (2014). Homeopatia na Estratégia Saúde da Família: apoio matricial e visão sistêmica cartografando a integralidade do cuidado. Rio de Janeiro.77 f. Dissertação [Mestrado Profissional em Atenção Primária à Saúde com Ênfase na Estratégia Saúde da Família] - Escola Nacional de Saúde Pública Sérgio Arouca.

Chaves, V. L. de V. et al. (2019) Resposta clínica e imunológica ao tratamento homeopático em portador de HIV: relato de caso. Rev. homeopatia (São Paulo), 82(1/2): 21-32.

Dias, J. de S., Melo, A. C. \& Silva, E. (2014). Homeopatia: percepção da população sobre significado, acesso, utilização e implantação no SUS. Espaç. saúde (Online), 15(2): 58-67.

Fontes, O. L. (2018). Farmácia Homeopática: Teoria e Prática. (3a ed.), Pubmedfon.

Herrera, M. M. C., \& Rodriguez, R. D. L. (2015). Panorámica Mundial del Mercado de los Medicamentos Homeopáticos a partir de las Plantas Medicinales. Revista Cubana Farm.39, n. 1

Júnior. E, T. (2016). Práticas integrativas e complementares em saúde, uma nova eficácia para o SUS. Metrópole E Saúde • Estud. av. 30 (86).

Lima, F., et al (2015). Uso de terapias integrativas e complementares por pacientes em quimioterapia. Av. enferm, 33(3):372-380.

Lima, S., et al (2019). Homeopatia no serviço público de saúde: pré-avaliação das ações no município do Recife (PE). Hist. ciênc. saúde-Manguinhos, 26(4): 1373-1391.

Loch-neckel, G., Carmignan, F., \& Crepaldi, M. A. (2016). A homeopatia no SUS na perspectiva de estudantes da área da saúde. Lilacs,

Melo, P. S. de \& Ito, R. (2018) Homeopatia: dificuldades e benefícios da implantação no sistema único de saúde e a importância da política nacional das práticas integrativas e complementares (PNPIC). Revista saúde. 11(2).

Menezes, M. J. R. (2018). A Homeopatia na promoção da Saúde. 64 f. Monografia (Especialização) - Pós-graduação em Homeopatia na área de Medicina Veterinária, Instituto Hahnemanniano do Brasil, Rio de Janeiro, Pubmed.

Mendes, D. S., et al (2019). Benefícios das práticas integrativas e complementares no cuidado de enfermagem. Journal Health NPEPS.

Nunes, Laila A. de Souza. \& Abrahão, F. A homeopatia como a arte de cuidar em saúde: análise da percepção dos usuários do SUS sobre o trabalho de homeopatia na cidade de Macaé/RJ. (2016). Rev. homeopatia (São Paulo), 79(1/2): 17-35.

Pereira, A. L. S. da, et al. Percepções sobre homeopatia na perspectiva de discentes dos cursos de saúde de um centro universitário de Recife-PE. (2021). Revista Sustinere, 9(1): 323-337.

Ruela, L. de O., et al (2019). Implementação, acesso e uso das práticas integrativas e complementares no Sistema Único de Saúde: revisão da literatura. Ciênc. saúde coletiva 24 (11) 28.

Silva, A. de O. G., et al (2021). Tratamento homeopático e sua implantação no SUS. Revista Ibero- Americana de Humanidades, Ciências e EducaçãoREASE. 2021.

Silva, J. B.T. et al (2019). Atendimento homeopático no Centro de Saúde da Barra Funda, SP: uma contribuição à atenção primária à saúde. Rev. homeopatia (Säo Paulo), 82(3/4): 26-33. 
Research, Society and Development, v. 10, n. 14, e317101421963, 2021

(CC BY 4.0) | ISSN 2525-3409 | DOI: http://dx.doi.org/10.33448/rsd-v10i14.21963

Souza, G. H. C. et al (2019). Uso da homeopatia no sistema único de saúde. Revista Saúde em Foco - Edição nº 11.

Schwarz, A., Pacheco, F. K., \& Ramos, R. F. (2014). Homeopatia no Sistema Único de Saúde. T. 40 p.

Teixeira, M. Z. (2019). Homeopatia: o que os médicos precisam saber sobre esta especialidade médica. Diagn. tratamento, 24(4): 143-152.

Tesser, C. D., Sousa, I. M. C. \& Nascimento, M. C. (2018). Práticas Integrativas e Complementares na Atenção Primária à Saúde brasileira. Saúde debate, 42(spe1): 174-188.

Toniol, R. F. (2015). Do espírito na saúde: oferta e uso de terapias alternativas/complementares nos serviços de saúde pública no Brasil. UFRGS - Repositório Digital. 